\title{
The Need for Strategic and Operational Planning in Adult Education: The Case of Greek Second Chance Schools
}

\author{
Magdalini Chira \\ Hellenic Open University, Patra, Greece \\ Georgios Errikos Hlapanis \\ Hellenic Open University, Patra, Greece
}

Dr. Vasiliki Brinia (corresponding author)

Hellenic Open University, Patra, Greece

Received: December 24, 2016

Accepted: December 31, 2016 Published: December 31, 2016

doi:10.5296/jet.v4i1.10656

URL: http://dx.doi.org/10.5296/jet.v4i1.10656

\begin{abstract}
The current research investigates the implementation of the planning within the training of the teaching staff in Second Chance Schools (S.C.S.) in Greece, through the perceptions of 90 teachers who work in these units, using quantitative and qualitative method and data collection tools, a structured questionnaire and a semi-structured interview. According to the findings, teachers confirmed the implementation of planning in the training programs as well as the implementation process of both the long-term strategic planning and the short-term operational planning within the training activities of educational units, procedures which are characterized by the participants as necessary for the organization and operation of schools and also for the achievements of their objectives.
\end{abstract}

Key-words: Planning, Adult Education Units, Strategic Planning, Operational Planning, Second Chance Schools, Teachers Training.

\section{Introduction}

The planning process in the field of education is the first and the most important step for the operation of management of each educational unit. It stands at the strategic and the operational planning, with the first involving long-term objectives of the unit and therefore general directions, while the second one involves short-term goals and daily functioning. In 
the Greek educational system, the pursuit of strategic planning is relatively limited, in contrast to the functional planning, which is widely applicable. Some of the exceptions are the adult education units and especially the Second Chance Schools (S.C.S.), where the institutional framework for their operation requires the implementation of both planning formats, as an integral part of the implementation of the school innovations, with the training of the teaching staff to be considered one of the most important. However, according to the study of international and Greek literature, it comes out that although the process of planning in education is a subject of study in recent decades, the issue of programming in S.C.S. has not been sufficiently explored, identifying a research gap to the exploration of the necessity of the strategic and the operational planning in the field of the staff training.

\section{Theoretical Part}

\subsection{The planning process}

In order to understand in depth the operation of planning in education, it is necessary to mention the essential elements. Specifically, planning is closely linked to decision-making, as it determines what is required to meet in the future and how it will be achieved, a function which includes some steps that are repeated and interacting (Saitis, 2008a).

Specifically, as presented in Koutouzis and Prokou (2005):

- Defining the objectives: the goals that an educational organization must achieve to continue to exist.

- Development of alternative solutions for the achievement of each objective, so that there is a choice between different solutions.

- Investigation of the circumstances and conditions of each possible solution, both in the internal and the external environment of the educational organization.

- Evaluation of alternatives, i.e. what is their impact for the educational organization.

- Select the best alternative, i.e. the selected action.

- Configure individual projects to achieve the final goal. The choice of the solution requires to create the conditions for its implementation.

- Implementation of the projects. After the implementation of the projects the other functions of administration, organization, management and control should follow.

\subsection{The types of planning}

The planning, depending on the level of administration in education and the timeframe in which goals are set (long term, short term), is distinguished in strategic planning and operational planning (Koutouzis \& Prokou, 2005).

The strategic planning, as outlined in Koutouzis and Prokou (2005), Chantzi (2005), Iasonidis (2010) and Papagrigorakis (2012), analyzes the environment of the educational organization. It could be said that strategic planning in an educational institution is long-term and refers to the wording of its mission, the analysis of external and internal environment, the assessment of their effects on setting the objectives and the study of problems that will probably occur in the allocation of resources to achieve these objectives. 
Operational planning in education is short-term. It refers to all the actions that implement the strategic objectives and takes place mostly in the middle and lower level management (Chang, 2008; Papagrigorakis, 2012). I.e., a coordinated set of activities for the implementation of objectives defined in a strategic plan, including the details of the strategic plan from which it originates. It has one year time horizon (Mittenthal, 2002) or less, depending on the educational organization.

The strategic and operational planning in education are in direct correlation with each other and they have equal value significance (Koronaiou, 2010). Operational includes daily activities in order to achieve the strategic objectives, i.e. its purpose is the practical application of strategic planning. Strategic planning, cannot be implemented without the activities of the operating planning. Both types of planning are, according to Mpourantas (2002), interrelated and complementary, as strategic objectives define the operational planing, thus forming a single function within the administration of education.

\subsection{Planning in Adult Education Units (ADU)}

As Mantzouka (2005) argues, the planning process in ADU refers mainly to the possibility of recognizing the mission of the school, the classification of a school project, the identification of objectives, taking into account strengths and weaknesses of the school unit to follow a course objectives approach, which will contribute to the fulfillment of the work of teachers. Therefore, a prerequisite for the rational planning in these units is, according to her, the participation of all stakeholders involved in school management in order to reflect and clarify the mission of the school, taking into account the current legal framework, the need to adapt education policy to the social and cultural developments, the local operating conditions and the school's "vision" for its social and educational role.

Planning in ADU is crucial as it contributes to the pursuit of internal education policy, which is related to the measures, actions and initiatives developed daily by the school unit and it aims at improving the provided educational work (Tasoula, 2006). The main task of the units is to apply the basic principles and the pedagogical approach defined by the European Union (EU) in adult education, including the design of open and flexible education programs, the use of innovative teaching methods and practices in order to exploit the knowledge and experience of the trainees. These result in personal and professional development and active participation in society and life (Mouzakis, 2006).Similar views were expressed by Kokkos (2004), stressing that ensuring quality design of these programs is an important factor in personal fulfillment and social inclusion, in order to meet the challenge of both economic revitalization and social cohesion.

Planning in the educational unit contributes to the improvement of the produced educational work, by shaping the character of the school unit, which is formed through specific policies, objectives and actions (Antonopoulou, 2010). Therefore, the planning activity of schools is a process, firstly regarding the implementation of the educational project, secondly adjusting the goals and objectives set by the Ministry of Education to the specific characteristics of each school unit and thirdly developing innovative programs and activities, which offer a variety of learning opportunities. 
Therefore, in order to achieve the principles of the EU, it is necessary to apply to the school unit both programming formats, strategic and operational, allowing teaching staff to actively participate. More specifically, the teacher as a member of the teaching staff, contribute to the creation of strategies that help to improving the education of learners, a crucial role to participatory decision-making, favoring the achievement of the objectives of the unit (Mantzouka, 2005; Antonopoulou, 2010). In addition, the teacher as researcher participating in the evaluation of educational work contributes to the adoption of innovative practices and proposals, namely the design and implementation of a plan of action that will be adjusted to the new situation, further contributing to the improvement while upgrading the educational work.

\subsection{Second Chance Schools in Greece}

In the European Commission's White Paper on Education and Training "Teaching and Learning: Towards the Learning Society" (European Commission, 1995), there is a mention of the Second Chance Schools (SCS). Greece adopted the Commission proposal and instituted the SCS as a flexible education program for adults, which gives an opportunity for people over 18 years who left school before completing their compulsory education, to continue the school in order to obtain equivalent qualification to the compulsory secondary education (Karalis, 2010). Specifically the objectives of SCS include:

- The completion of compulsory education of citizens.

- The reconnection of learners with education and training systems.

- The acquisition of modern knowledge, skills and attitudes that will help them in social-economic integration and development.

- The strengthening of self-esteem of learners.

- The contribution to integration or improvement of their position in the workplace.

The SCS, as an institution, aims at creating open and flexible schools, which differ from the formal educational system. SCSs develop innovations, such as the adoption of literacy in educational practice, innovative training methods and techniques, training teaching staff, evaluation of trainees, etc. (Chaldoupi, 2014). The main priority of SCS is the student, aiming at the development of metacognitive skills, to boost the self-esteem and the active participation in society and life, in order to counteract the risk of marginalization and social exclusion. Specifically, the SCSs' curriculum emphasizes in the basic skills of learners, such as writing, reading, counting, new technologies and the learning of a foreign language (Chaldoupi, 2014).

In order to implement what has been said, it is necessary, the adult educator to adopt innovative teaching methods and techniques in order to meet the learning needs of the students in cognitive level and in terms of strengthening their social skills (Chaldoupi, 2014).

Another important innovation of SCS is the continuous education and training of teachers, which aims, according to Koutouzi and Prokou (2005), to their participation in the school administration and to improve services. In particular, for the upgrading of the learning process at each SCS there are scientific and thematic coordinators, who are in constant 
communication with teachers, while there are scheduled training sessions with all teachers, which consist the exchange of experiences and provide a framework of principles and actions. Therefore, the training of the teaching is considered extremely necessary on the process of conquering the professional knowledge, which, according to Papatrechas (2012), should be related to the basic principles and philosophy of adult education, the pedagogy, the characteristics of learners and the ways of detecting their training needs.

Therefore, it is necessary for the research to focus on one of the innovations of the institution and in particular the training and development of the teaching staff of the organization, a field in which the implementation of planning is considered necessary because it ensures the improvement of education.

\section{Research Part}

\subsection{Purpose of the research}

The purpose of this research is to examine the planning and its importance for the ADU correlating the necessity of strategic and operational planning to SCS by training the educators.

Specifically, through the collection and analysis of the date data, it will be recorded, whether the SCS apply the process of planning in training programs for educational staff. Furthermore, we try to investigate the perceptions of teachers of SCS on the implementation of long-term strategic planning as part of staff training, and finally, to present their ideas about the actions that are required in order to implement the strategic objectives in the training field.

More specifically:

1. Do SCS apply the function of planning in education staff training programs?

2. Do SCS implement the process of long-term strategic planning in the context of the teaching staff training?

3. Do SCS implement the process of short-term operational planning within the education staff training?

\subsection{Methodology}

The research is based on the mixed process of triangulation combined with the quantitative research using a structured questionnaire and qualitative research using the semi-structured interview. This choice aims to examine the perceptions of participants from different perspectives (Cohen \& Manion, 1994), while seeking to highlight the advantages of each method, as one complements the other. Robson (2010) argues that the use of multiple methods complement and reinforce the research process, while ensuring its reliability and validity. Therefore, in a quantitative survey the interpretation of the statistical analysis is enhanced by the qualitative narrative data, guaranteeing optimal understanding of the research problem.

According to Creswell (2011), by using the quantitative method, the researcher "conducts the investigation in an impartial and objective manner" (p. 66), decreasing the interference of the researchers to a minimum (Muijs, 2010)and ensuring a high degree of objectivity, representativeness, validity and reliability (Tsiolis, 2011). Additionally, the qualitative method 
can ensure a warm climate between the interviewer and the interviewee (Antonopoulou, 2010), with the second to have full freedom in formulating the answers (Vamvoukas, 2000).

To digitize and statistical analyze the quantitative data we used the Statistical Analysis Package for Social Sciences v.22 and Microsoft Excel 2010 software, which was developed to graphically reflected the results of the research. For the analysis of the qualitative data we used the scientific analysis of the content in order to classify the content of the material into categories for the purpose of analysis and drawing conclusions.

\subsection{Sample}

The research was based on nonprobability sampling, in which, like Creswell (2011) states, "the researcher selects individuals because they are available, convenient, and represent a characteristic that wants to study" (p. 182), or as he points out, "volunteer and who agree to study" (p. 182). Specifically, the snowball sampling approach was used, in which, according to Creswell (2011), «the researcher asks participants to indicate who can become member of the sample" (p. 183). The main factor of this choice was that the "recruitment" of some specific individuals, could lead to larger numbers of participants, regions in which SCS are operating.

Therefore, the sample of this study consists of teachers of SCS, who come from 27 schools from the regions of Attica, Eastern Macedonia and Thrace, Central Macedonia, Western Greece, Epirus, Central Greece and the Peloponnese. The sample size for the quantitative approach includes 87 teachers, while respectively for the qualitative approach there are three teachers.

\subsection{Methodology tools}

As data collection tools for this research the structured questionnaire and the semi-structured interview were selected.

The choice of the questionnaire as a research tool ensures that all respondents answer the same questions, it is quickly completed, while conditions for the respondents are the same. In addition, the information collected through the questionnaire is, according to Cohen and Manion (1994), Bird (1999), Faulkner (1999) and Athanasiou (2003), more reliable. The questionnaire can ensure anonymity and participants can express themselves honestly (Papagrigorakis, 2012). The questionnaire, as a research tool, is economical, allows large research sample is it can be carried out in a short time, and the analysis of the is easy using statistics methods.

The interview is a research tool that allows an in-depth investigation of the issue, analyzing and interpreting situations or experiences (Kedraka, nd). The interviews provide useful information when the observation of participants is not possible, and often act as a means of explaining the questionnaire results. The interviews, according to Creswell (2011), «have resulted in a high response rate because the researchers plan interviews in advance and the sample participants usually feel compelled to complete the interview" (p. 433). Important advantages of this method is the immediacy between interviewer and interviewee and the 
possibility to collect a lot of information in a short time (Chaldoupi, 2014).

\section{Results}

\subsection{Quantitative results}

$1^{\text {st }}$ question: Do SCS apply the function of planning in education staff training programs?

The level of the implementation of planning in staff training is high, with the option "Enough" to collect the $70,11 \%$. The way of exercising operational planning is empirical $(33.33 \%)$ and scientifically $(66.67 \%)$. The needs of staff in accordance with which the training should be planned are:

- Education: 18 (20.69\%) participants answered "A lot", 51 (58.62\%) "Enough", 16 (18.39\%) "Little" and 2 (2.30\%) "Not at all".

- Years of experience: 1 (1.15\%) participant replied "A lot", 36 (41.38\%) "Enough", 39 (44,83\%) ":Little" and $11(12.64 \%)$ "Not at all".

- Training needs in teaching, 45 (51.72\%) participants answered "A lot", 41 (47.13\%) "Enough" 1 (1.15\%) "Little" and none "Not at all".

- Training needs in adult education, 80 (91.95\%) participants answered "A lot", 7 $(8.05 \%)$ "Enough", while none replied "Little" nor "Not at all".

On the type of programming promoted by SCS all 87 (100.00\%) participants answered that both kinds of programming, strategic and operational are promoted.

$2^{\text {nd }}$ question: Do SCS implement the process of long-term strategic planning in the context of the teaching staff training?

Referring to the implementation of the strategic planning, the respondents answered "A lot" (16\%), "Enough" (77\%) and "Little" (7\%) .

Regarding the time horizon of planning, 78 (89.66\%) participants answered "Up to 1 school year" and 9 (10.34\%) "More than one school year." Regarding the satisfaction of implementing the planning, 17 (19.54\%) participants answered "A lot", 60 (68.97\%) "Enough", and 10 $(11.49 \%)$ "Little". The way of achieving the strategic planning within the framework of training is characterized by $85(97.70 \%)$ participants as "a continuous process by involving all the teaching staff in the formulation and implementation" and 2 (2.30\%) as "A typical process imposed by the SCS Administration". Regarding the necessity of the strategic planning in training programs $62 \%$ of the participants ansered "A lot" and 32\% "Enough".

In regards to the extent that the participants believe that the strategic planning that takes place in SCS for staff training, is implemented in the right way, it appears that it is exercised quite properly ("A lot" 16\%, "Enough" 71\%, "Little” 13\%).

Referring the level of importance for the SCSs' effectiveness, the respondents believe that the process of long-term planning in the design of training is "A lot" $(62 \%)$ and "Enough" $(38 \%)$ important. 
The criteria to be taken into account by the SCS in the long-term strategic planning in the context of training are the following:

- Vision for the future of SCS, 2 (2.30\%) participants answered "A lot", 54 (62.07\%) "Enough" and 31 (35.63\%) "Little".

- Mission of the SCS, 36 (41.38\%) participants answered "A lot" and 51 (58.62\%) "Enough".

- Objectives of SCS, 53 (60.92\%) participants answered "A lot" and 34 (39.08\%) "Enough".

- Training budget, 73 (83.91\%) participants answered "A lot" and 14 (16.09\%) "Enough"

- Choosing the most appropriate solution, 25 (28.74\%) participants answered "A lot", $61(70.11 \%)$ "Enough" and $1(1.15 \%)$ "Little"."

- Pattern of individual projects, 11 (12.64\%) participants answered "A lot", 54 (62.07\%) "Enough" and 22 (25.29\%) "Little" .

$3^{\text {rd }}$ question: Do SCS implement the process of short-term operational planning within the education staff training?

Regarding the implementation of operational planning for the daily activities in the context of training, where participants answered "A lot" (67\%) and "Enough" (33\%). In regards to the satisfaction by implementing the operational program, 32 (36.78\%) participants answered "A lot", 51 (58.62\%) "Enough" and 4 (4.60\%) "Little". Operational planning within the framework of training is characterized by $85(97.70 \%)$ participants as "a continuous process by involving all the teaching staff in the formulation and implementation" and $2(2.30 \%)$ as "A typical process imposed by the SCS administration.

Afterwards, the necessity for operational planning in training programs is presented ("A lot" $77 \%$, "Enough" 23\%). The importance of the process of operational planning in the design of training is presented ("A lot" 38\%, "Enough" 62\%).

The criteria to be taken into account by the SCS in the short-term strategic planning in the context of training are the following:

- Specific objectives for the implementation of strategic plans: 24 (27.59\%) participants answered "A lot", 47 (54.02\%) "Enough" and 16 (18.39\%) "Little". Selection of action plans to improve current operations, 40 (45.98\%) participants answered "A lot" and 47 (54.02\%) "Enough" and "little"

- Budget for each project, $76(87.36 \%)$ participants answered "A lot" and 11 (12.64\%) "Enough".

- Personal needs of staff, 10 (11.49\%) participants answered "A lot", 52 (59.77\%) "Enough" and 23 (26.44) "Little".

- Developments in adult education, 38 (43.68\%) participants answered "A lot", 45 $(51.72 \%)$ "Enough" nad 4 (4.60\%) "Little".

- Developments in the specialties of teachers, $16(18.39 \%)$ participants answered "A lot", 58 (66.67\%) "Enough" and 13 (14.95\%) "Little". 
Regarding the investigation to what extent the implementation of the operational program contributes to the effective implementation of the training, "A lot" occupies the first place (76\% and "Enough" 24\%).

\subsection{Qualitative results}

$1^{\text {st }}$ question: Do SCS apply the function of planning in education staff training programs?

All interviewees reply that that planning is applied to the training and highlight its necessity.

$2^{\text {nd }}$ question: Do SCS implement the process of long-term strategic planning in the context of the teaching staff training?

Respondents in regards to whether the SCS implements the process of long-term strategic planning in training programs, characterize strategic planning as an essential part of the process of planning of the training activities, which helps in the utilization of school opportunities and is implemented through the cooperation of all of the teachers' association members. However, they stressed the lack of stable staff in SCS.

Regarding the horizon of the strategic planning, all teachers agree on annual strategic planning, which, as mentioned, is determined primarily by the full staffing of SCS. In the question about whether the process of long-term planning is essential for the effectiveness of SCS within the design of the training, all found it to be significant, emphasizing the collective effort made by all the teachers in each SCS. This effort is considered a key factor in the design of training activities, the proper functioning of schools and producing a more qualitative work, which results in the effectiveness of each unit.

Afterwards, regarding the criteria which must be taken into account by the SCS in strategic planning shows that common element is the financial resources and staff, while only one of the respondents also included the objectives set by the SCS. Referring to the frequency of the evaluation for the objectives set in the strategic planning in the context of training, the respondents claimed that there is a the short time horizon for achieving the objectives and also lack of time. These reasons prevent their review.

The next question on whether the school analyzes the environment in the context of training, show that there is an attempt, underlining that the experience of the previous years direct the way towards which they will work. However, sometimes it is not done thoroughly, mainly due to lack of time.

$3^{\text {rd }}$ question: Do SCS implement the process of short-term operational planning within the education staff training?

Participants agree that the SCS implements the process of operational planning for the organization of daily activities in the training of teaching staff. Furthermore, they consider it as an extremely important process for the implementation of strategic planning, which helps to move into a framework of certainty, stressing that there are no firm commitments for its implementation.

Regarding the process of short-term planning in the effectiveness of SCS within the design of 
the training, all participants emphasize the importance of daily actions for the successful organization of training programs, which improves simultaneously the effectiveness of the SCS.

Concerning whether the application of operational planning in SCS contribute to the effective implementation of the training, the common belief is that all contribute, stressing that they are based on collaborative work.

\section{Conclusions}

The planning process in the field of education is the first and the most important step for the operation of management of each educational unit. It stands at the strategic and the operational planning, with the first involving long-term objectives of the unit and therefore general directions, while the second one involves short-term goals and daily functioning. In the Greek educational system, the pursuit of strategic planning is relatively limited, in contrast to the functional planning, which is widely applicable. Some of the exceptions are the adult education units and especially the SCS, where the institutional framework for their operation requires the implementation of both planning formats, as an integral part of the implementation of the school innovations, with the training of the teaching staff to be considered one of the most important. However, according to the study of international and Greek literature, it comes out that although the process of planning in education is a subject of study in recent decades, the issue of programming in S.C.S. has not been sufficiently explored, identifying a research gap to the exploration of the necessity of the strategic and the operational planning in the field of the staff training.

Regarding the first research question, it derives from both research methods, that the application of planning in these programs, with a percentage of $98.89 \%$, highlights the active participation of the Teachers' Association, as a determining factor for the implementation of this operation. In particular, from the findings obtained by the quantitative approach, it is important that all participants responded positively to the implementation of the planning of both types, a fact which shows that the staff of SCS understands that the planning is essential for the management and organization of the school. Additionally, it contributes to the development of initiatives and in order for the educational unit to achieve its objectives in the context of training, taking into account the needs of teachers. These findings are confirmed by the qualitative approach, the results of which show that teachers in SCS know the importance of operational planning and its necessity. The participants consider that the application of this process contributes positively to their efforts and therefore the objective of the school unit, which is to improve the through the active participation of the Teachers' Association and the collective efforts of its members. These factors are an essential piece for the normal functioning of the educational unit and the implementation of its mission.

From the second research question, the implementation of strategic planning training courses is derived. This contributes to the rational exercise of the function of administration (approximately 93.33\%), being a process in which, according to the findings, the participants must set goals, analyze the environment of the educational unit, in order to implement the mission through collective efforts. In particular, the quantitative approach shows the staff's 
satisfaction by implementing strategic planning training courses, the implementation of which is considered essential for the training programs. It is apparently, a process that involves all the teaching staff in the formulation and implementation, thus contributing to the effectiveness of the school. Similarly, the qualitative approach deriving similar findings, that the application of the process of strategic planning in training programs is a regulatory factor in the organized implementation, an element that contributes positively to the work of teachers and therefore the successful completion of the mission of the unit. Noted that important factors for the implementation of long term planning are an analysis of the environment and the teamwork and effort, data that teachers consider necessary in order to resolve possible problems and the unit to operate efficiently, realizing its goals successfully.

The SCS implement the process of short-term operational planning within the education staff training and all participants consider the operational planning as a criticala process in realizing the strategic objectives. In particular, the quantitative approach shows that staff is satisfied by implementing the operational programming in training programs which they consider necessary for the implementation of strategic objectives. It is a process that involves all the teaching staff in the creation and implementation, thus contributing to the effectiveness of the school.

In addition, the findings of a qualitative approach, reveal that the application of the operational planning process to staff training programs is a necessary process, which contributes to the better implementation of training programs. Through the daily actions of in training activities the implementation becomes successful, and consequently the effectiveness of the school unit, in accordance with the targets set in the strategic planning. It is considered as an outcome which derives from the collective effort of the staff and the rational planning of daily activities, along with the personal discretion of each teacher to ensure the quality of training.

\section{References}

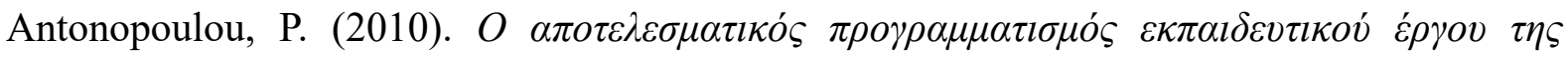

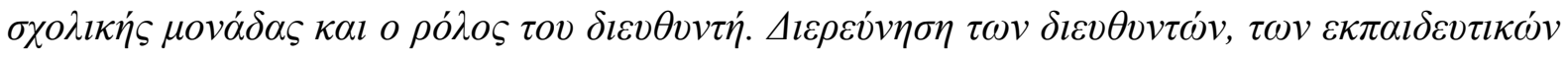

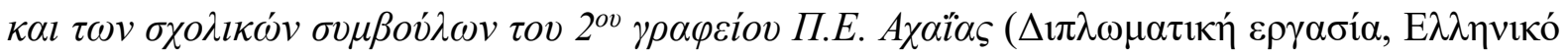

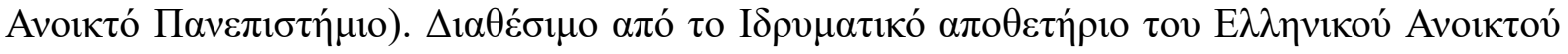

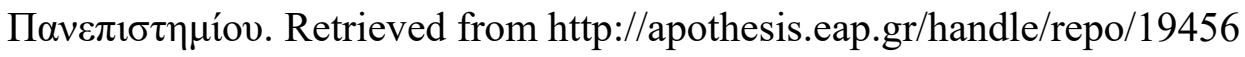

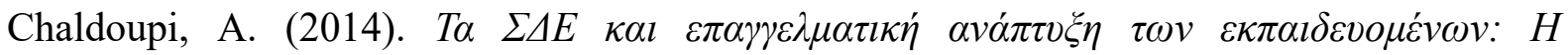

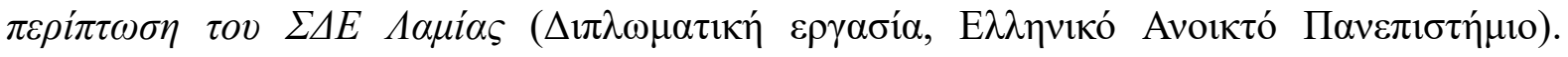

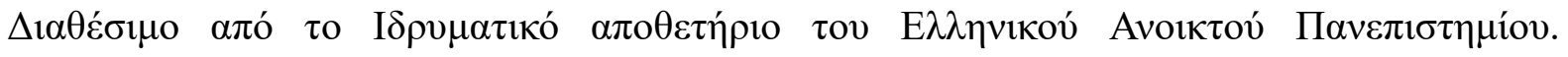
Retrieved from https://apothesis.eap.gr/handle/repo/27559

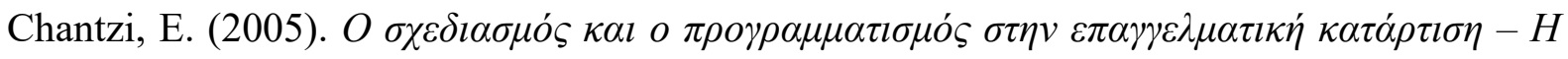

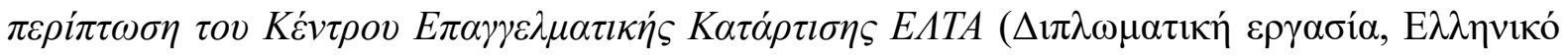

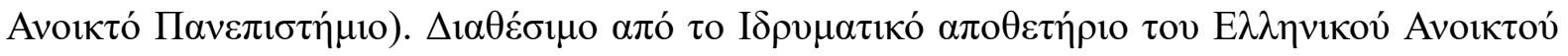

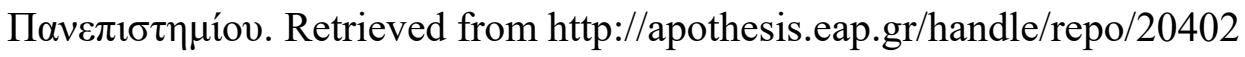

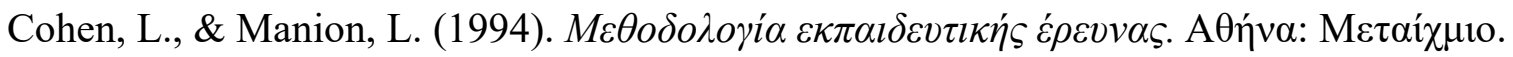




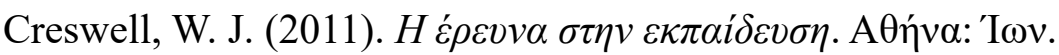

European Commission. (1995). White Paper on education and training. Teaching and Learning: towards the Learning Society. Brussels: E.C.

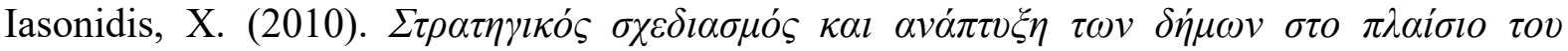

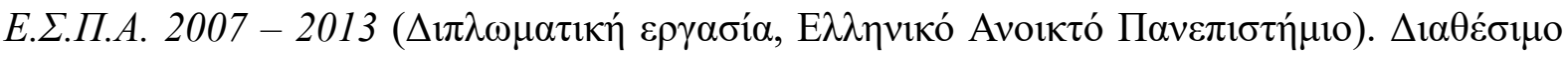

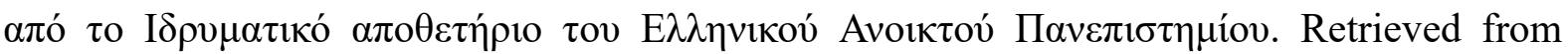
http://apothesis.eap.gr/handle/repo/18026

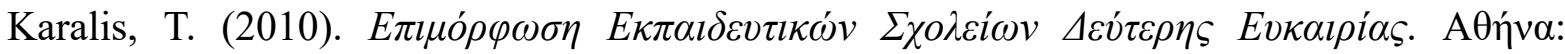

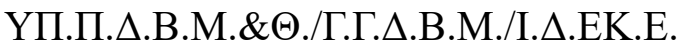

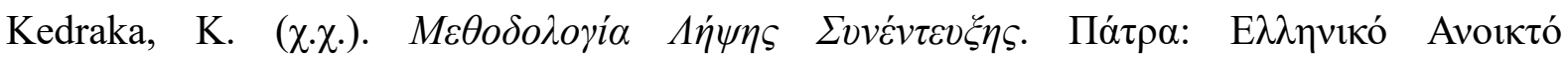

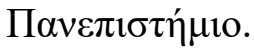

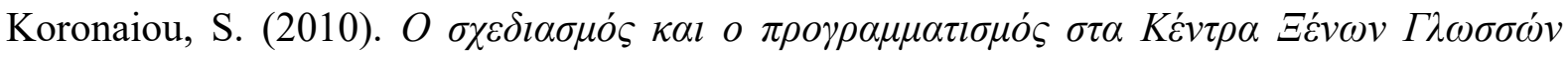

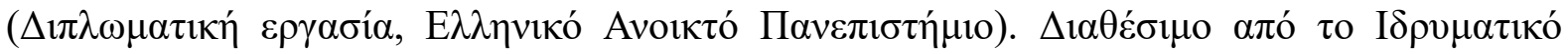

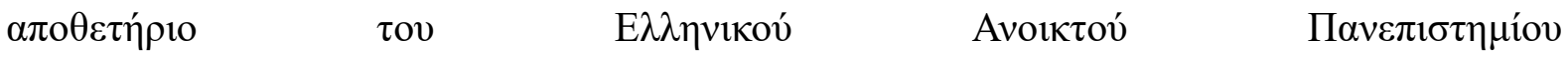
(http://apothesis.eap.gr/handle/repo/19462).

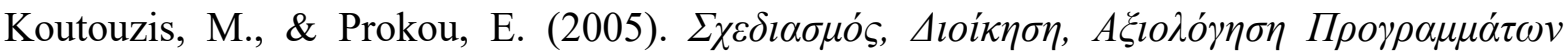

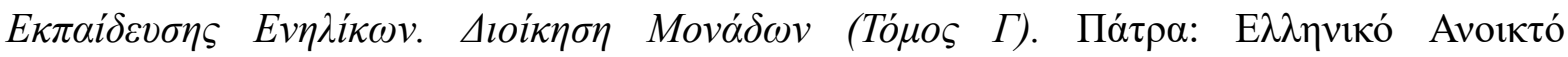

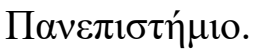

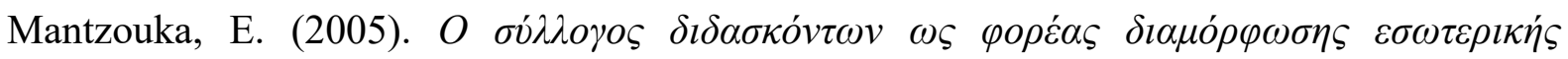

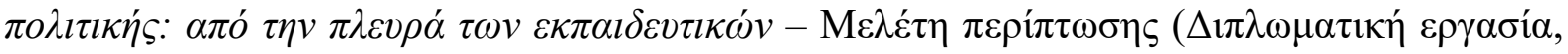

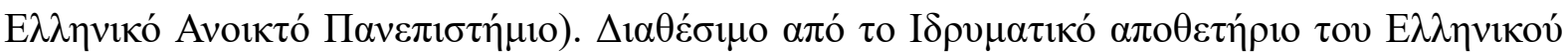

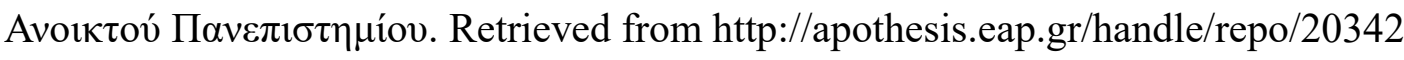

Mittenthal, R. (2002). Ten Keys to Successful Strategic Planning for Nonprofit and

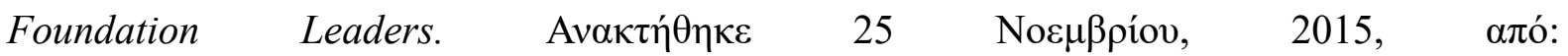
http://www.tccgrp.com/pdfs/per_brief_tenkeys.pdf

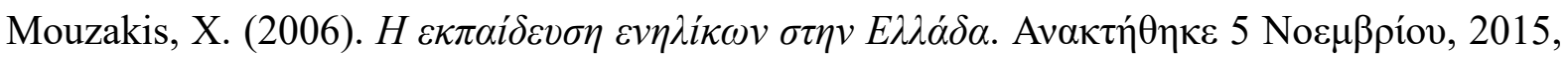
$\alpha \pi$ ó. Retrieved from http://repository.edulll.gr/edull1/retrieve/2532/782.pdf

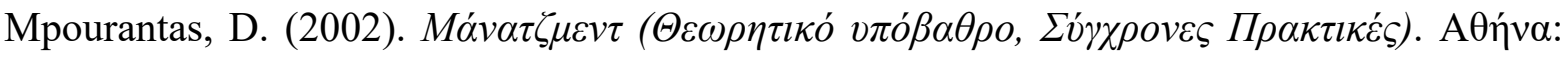
M $\pi \dot{v}$ ov.

Muijs, D. (2010). Doing Quantitative Research in Education with SPSS (2nd ed.). London: SAGE.

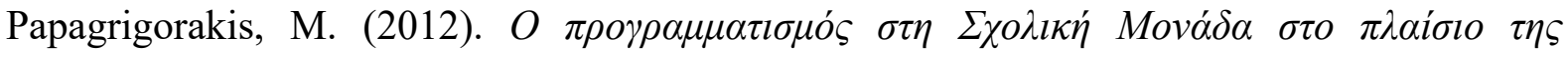

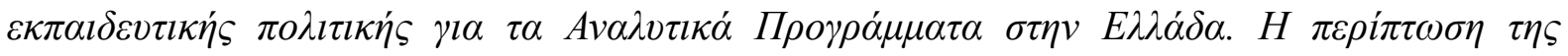

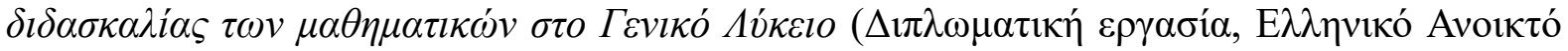

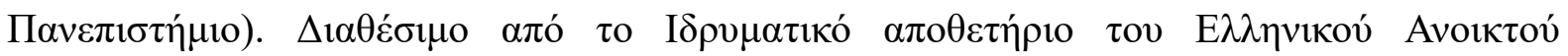

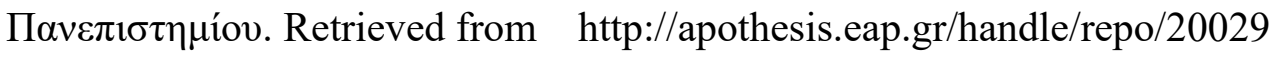

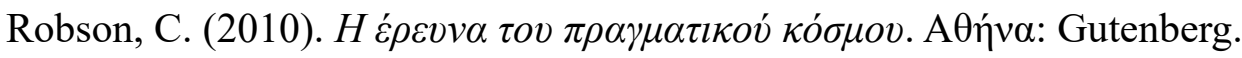




\section{Macrothink}

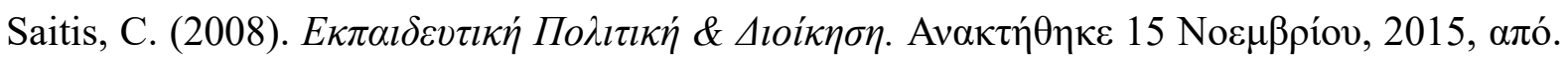
Retrieved from http://repository.edulll.gr/edulll/handle/10795/1093

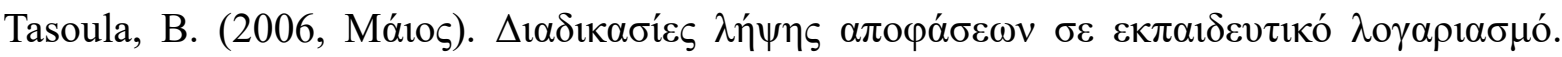

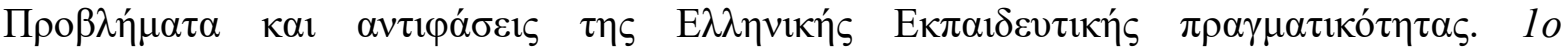

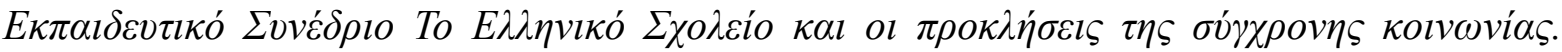

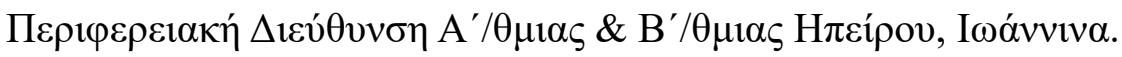

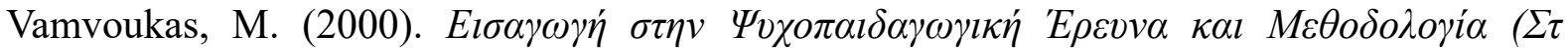

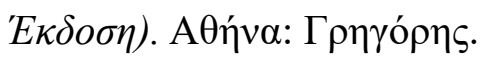

\section{Copyright Disclaimer}

Copyright reserved by the author(s).

This article is an open-access article distributed under the terms and conditions of the Creative Commons Attribution license (http://creativecommons.org/licenses/by/3.0/). 